WSRC-TR-92-12

TASK $91 \cdot 086-1$

\title{
EMT
}

EQUIPMENT AND MATERIAL TECHNOLOGY

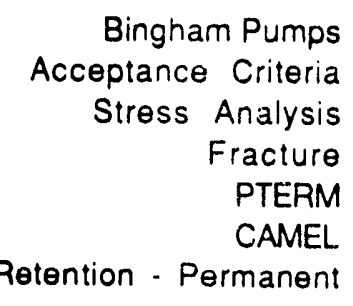

\section{STRUCTURAL INTEGRITY ANALYSIS OF PROCESS WATER SYSTEM BINGHAM PUMPS (U) \\ TASK NUMBER: 91-086-1}

By

N. K. Gupta N.K. Stapta

ISSUED: October 1992

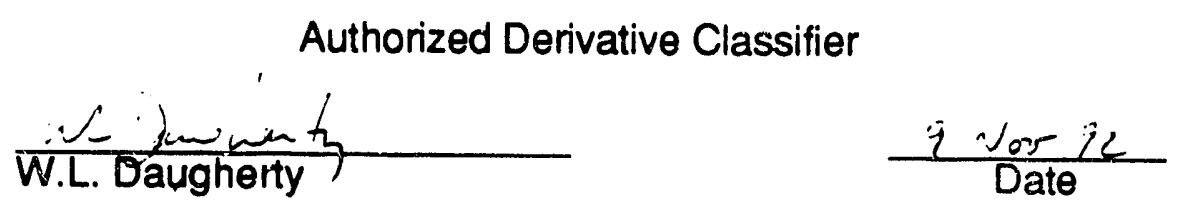

SRTC SAVANNAH RIVER TECHNOLOGY CENTER, AIKEN, SC 29808

Westinghouse Savannah River Company

Prepared for the U. S. Department of Energy under Contract DE-AC09-8qSR18035 
PROJECT: ACCEPTANCE CRITERIA DEVELOPMENT FOR PWS COMPONENTS

DOCUMENT: WSRC.TR.92.12

TITLE: STRUCTURAL INTEGRITY EVALUATION OF PROCESS WATER SYSTEM BINGHAM PUMPS (U)

TASK: $\quad 91.086 \cdot 1$

TASK TITLE: ACCEPTANCE CRITERIA FOR BINGHAM PUMPS

APPROVALS

$$
\text { P. ThS }
$$

P. S. LAW, TECHINICAL REVIEWER MATERIALS TECHNOLOGY SECTION

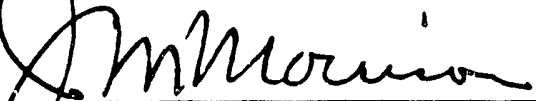

J. M. NORIISON, CUSTOMER REVIEW REGULATORY TECHNICAL PROGRAM

$$
\text { N.G. Qusdalle }
$$

N. G. AWADALLA, MANAGER MATERIALS TECHNOLOGY SECTION

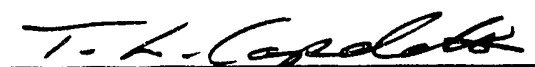

T. L. CAPELEITI, MANAGER MATERIALS TECHNOLOGY SECTION
DATE: November 10,1992

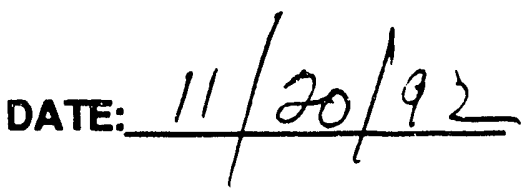

DATE: $12-14-92$ DATE: $/ 2 / 1 T / 92$ 


\section{EXECUTIVE SUMMARY}

Bingham pumps comprise part of the pressure boundary of the Process Water System (PWS). Monitoring the pump casing through in-service inspection is important to demonstrate the structural integrity throughout service. An acceptance criteria methodology with technical bases is provided to disposition flaws detected during examination of the pump casing. The methodology ensures that the defined structural or safety margins ${ }^{1}$ against failure are maintained throughout pump service in full consideration of service-induced degradation. 2

Acceptance criteria, defining the acceptable flaw (length and depth) configurations for the pump casing, are established through structural analyses of the casing and flaw stability analyses of postulated flaws. Three-dimensional shell element model of the complex-shaped casing is constructed and detailed finite element stress analyses are performed at normal and off-normal loading conditions. Safety factors are applied to the resultant stresses and flaws are postulated at the most highly stressed regions of the pump casing. Postulated throughwall flaws in simplified casing configurations are analyzed with linear elastic and limit load methods with conservative application of the stress results. The most limiting results from the flaw stability analyses define the acceptable flaw length of 3.5 " for the casing.

The acceptable flaw length is established based on the flaw stability solutions for throughwall cracks. To limit the flaw depths for leakage prevention, the acceptable depths for the flaws are set to $75 \%$ of the body thicknesses for flaws with lengths up to the acceptable flaw length. This $75 \%$ depth criterion is consistent with the maximum acceptable depth provided by the ASME Boiler and Pressure Vessel Code. ${ }^{3}$

The acceptance criteria provide the limiting flaw configuration for the pump to remain in service and thereby maintain the defined safety margins against failure. An acceptance criteria methodology for flaw disposition in the in-service inspection of the pump is developed with guidance from Section $\mathrm{XI}$ of the ASME B\&PV Code for inspection requirements for pump casing and casing welds and from Code Case $\mathrm{N}-481$ which is specifically written for examination requirements for cast austenitic pump casings. The methodology ensures that the pump casing acceptance criteria are met throughout pump service.

The pump suction cover was separately analyzed to study the bolt failure concerns. Analyses were performed considering all bolts intact, all bolts cracked (25\% deep through minor diameter), and up to 8 bolts inactive. It is found that as many as 4 bolts could be completely broken without adversely impacting the pressure boundary of the pumps at the design and operating conditions. Therefore, the current practice of volumetric and surface examination of the suction cover bolts is sufficient for the continued safe operation of the pumps.

1 Safety margins for flaws in the pressure boundary of the SRS reactor PWS are adopted from Section XI of the American Society of Mechanical Engine'rs Boiler and Pressure Vessel Code, Article IWB-3642 for austenitic steel piping and are a factor of 3 on the normal operation (or design) loads and a factor of 1.5 on the loads under emergency/faulted (off-normal) conditions including transients. The normal loads include pressure, deadweight, and/or thermal loads. The off-normal loads include normal operation plus seismic forces or water hammer pressures.

2 The Bingham pump bodies are constructed of CF8, the cast equivalent of Type 304 stainless steel, and are not predicted to be susceptible to in-service degradation causing cracking, thinning, or embrittlement.

3 Section XI of the American Society of Mechanical Engineers Boiler and Pressure Vessel Code, Article IWB-3641, for austenitic steel piping. 


\section{WSRC-TR-92-12 \\ TABLE OF CONTENTS}

Section

1.0 INTRODUCTION

1.1 Background

1.2 Inspection of the Bingham Pumps 1 1

2.0 MATERIALS OF CONSTRUCTION

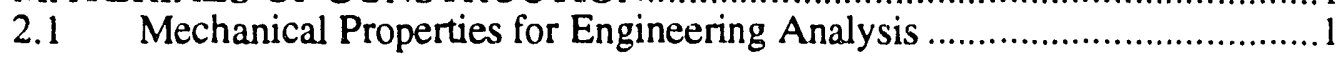

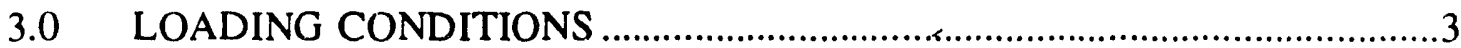

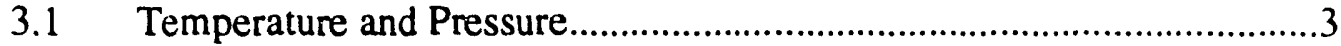

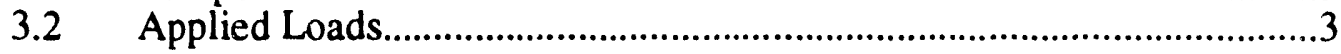

4.0 FINITE ELEMENT MODEL AND FRACTURE ANALYSIS .........................

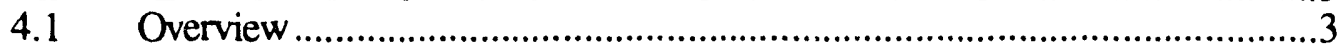

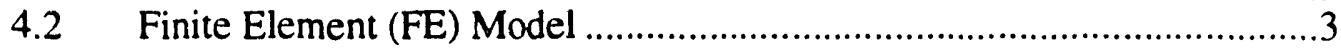

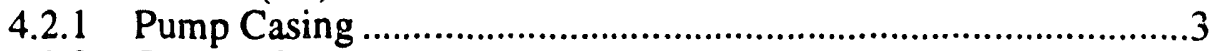

4.2.2 Suction Cover ...........................................................................4

$4.3 \quad$ Finite Element (FE) Mesh.............................................................. 4

4.3.1 Pump Casing .........................................................................4

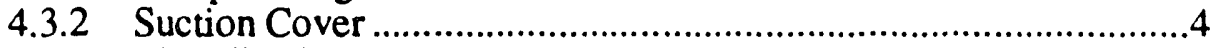

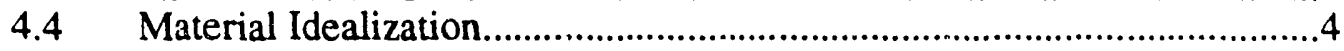

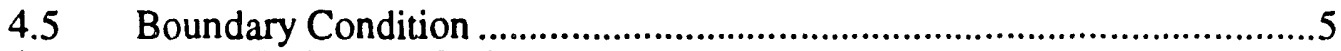

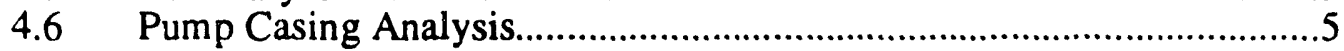

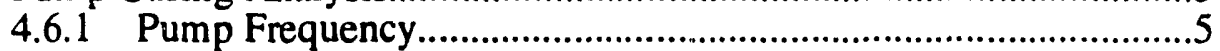

4.6.2 Pump Casing Stress Code Check ..............................................5

4.6.3 Pump Casing Fracture Analysis..............................................6

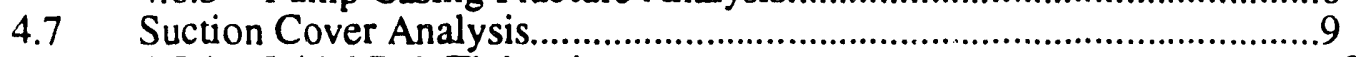

4.7.1 Initial Bolt Tightening .............................................................. 10

4.7.2 Bolt Stress Analysis..................................................................11

4.7.3 Bolt Fatigue Analysis.............................................................12

4.7.4 Bolt Fracture Analysis ............................................................ 12

5.0 ACCEPTANCE CRITERIA METHODOLOGY FOR THE BINGHAM

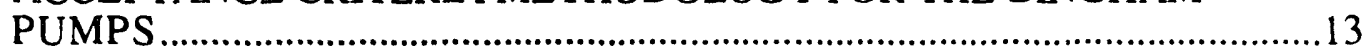

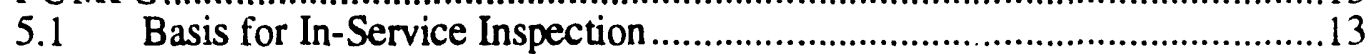

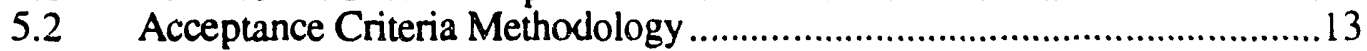

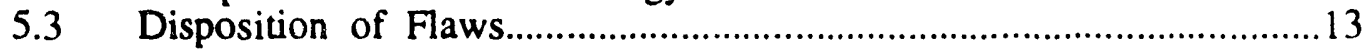

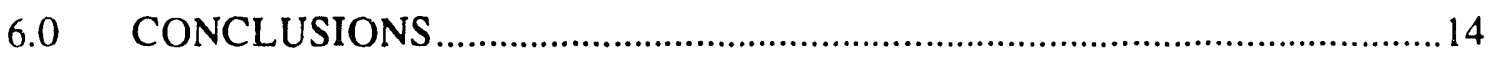

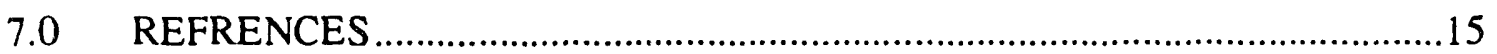

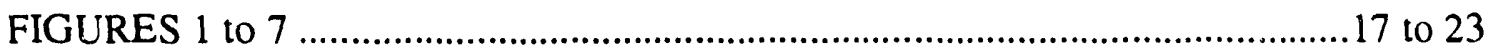




\subsection{INTRODUCTION}

\section{$1.1 \quad$ Background}

The SRS process water recirculation pumps are called Bingham pumps. The pumps are double suction, double volute, radially split type pumps. This design is designated as Type D in the ASME Code. (Ref. 1). The pumps are classified as Safety Class 1 in Table 3.2-1 of the K-Reactor Safety Analysis Report, however, only manufacturer's standards are specified as the construction code. Due to the complexity of the pump casing details and the fact that the casing thickness is large for the temperatures and pressures involved, the detailed structural integrity analyses are not routinely performed for such cast components. Some design rules regarding casing wall thickness and geometrical details are given in Reference 1. However, ASME Code Case N-481 (Ref. 2) requires that in lieu of volumetric examination of the pump casings, a detailed stress analysis should be performed which should then be followed by a flaw evaluation to demonstrate flaw stability of a postulated flaw. For Bingham pumps, no such detailed analysis has been performed.

A simplified structural analysis was performed by Brookhaven National Laboratory in December 1989 (Ref. 3). This analysis approximated pump casing with beam elements and calculated the seismic response. The results from this type of analysis are not conducive to flaw evaluation. Another simplified analysis (Ref. 4) covered the bolts of the suction cover. This analysis concluded that the bolt stresses are small under maximum pressure conditions and a periodic inspection would suffice to ensure their structural integrity. This analysis did not cover the scenario in which cracks could develop in some bolts of the suction cover.

A review of the incident reports for the Bingham pumps shows that no incidents are related to failures of the pressure boundary. However, failures have been associated with mechanical seals around the pump shaft and pressure sensing lines. Other failures have been due to electrical and mechanical failures of the components.

The analysis in this report will evaluate the overall structural integrity of the Bingham pump casing including the suction cover. The design criteria will be taken from ASME Code, Section III (Ref.1). The bearings at the two ends of the pump are not covered in this analysis as they do not form a part of the process water pressure boundary.

\subsection{Inspection of the Bingham Pumps}

The Bingham pumps are visually inspected per DPSOL 1851B (Ref. 5). The components inspected are usually throttle bushings, impeller and impeller rings, pump coupling, pumn casing and wear rings, and thrust bearings. The usual observations are of wear scars, pits on wear rings, and scratches caused by tiny pieces of debris trapped between the mating surfaces. Small pits have been noticed on the casing and suction cover $\mathrm{O}$-ring surface, but no cracks have ever been found. No cavitation or erosion damage has been found on the casing.

\subsection{MATERIALS OF CONSTRUCTION}

The pump casing and suction cover are made of Type 304 stainless steel (Ref. 6). These are cast components. The bolts holding the suction cover are made of high strength steel A-193 Gr B7. The materials of construction of other parts are given in Reference 4.

\subsection{Mechanical Properties for Engineering Analysis}

A value of 0.3 is used for Poission's ratio for Type 304 stainless steel material. A single lower bound fracture toughness property is given as $\mathrm{J}_{\mathrm{IC}}$ (Ref. 7) or the equivalent linear elastic parameter 
$\mathrm{K}_{\mathrm{IC}}$ for fracture analysis of the casing or suction cover. Table 1 below lists the fracture properties used in the flaw evaluation analysis.

Table 1 - Fracture Toughness for Type 304 SS and A-193 Gr B7

\begin{tabular}{|l|l|l|l|l|}
\hline Material & $\begin{array}{l}\text { Test } \\
\text { Temperature }\left({ }^{\circ} \mathrm{F}\right)\end{array}$ & $\begin{array}{l}\text { Sample ASTM } \\
\text { Orientation }\end{array}$ & $\begin{array}{l}\text { JIC-Deformation } \\
\left(\mathrm{kJ} / \mathrm{m}^{2}\right)\end{array}$ & $\begin{array}{c}\mathrm{K}_{\mathrm{IC}} \text {-Deformation } \\
(\mathrm{ks} \sqrt{\mathrm{im})}\end{array}$ \\
\hline 304 SS Base & 257 & $\mathrm{C}-\mathrm{L}$ & 338 & 230 \\
\hline A-193 Gr B7 & 68 & N/A & 108 & 134 \\
\hline
\end{tabular}

A-193 Gr B7 is used for high-strength bolting. This material is a low alloy steel and is equivalent to AISI 1040, 1042, or 1045 steels. Fracture toughness $\mathrm{K}_{\mathrm{IC}}$ is derived from Charpy V-Notch (CVN) test data at room temperature. A CVN value of $46 \mathrm{ft}-\mathrm{lbs}$ is obtained at room temperature. Since the operating temperature is higher, this is a conservative value. The following empirical relation (Ref. 8) is used to estimate $\mathrm{K}_{\mathrm{IC}}$.

$$
\frac{\mathrm{K}_{\mathrm{IC}}^{2}}{\mathrm{E}}=0.22 \times(\mathrm{CVN})^{1.5} \quad \text { Eq. } 4.7 \text { of Ref. } 8
$$

The CVN units in the above equation are Joules and the left hand side units are $\mathrm{kPa}-\mathrm{m}$ (kilo Pascals-meter). Using the relationship $\mathrm{K}_{\mathrm{IC}}^{2} / \mathrm{E}=\mathrm{J}_{\mathrm{IC}}$ for Linear Elastic Fracture Mechanics (LEFM) regime in plane stress and converting to the $\mathrm{ksi} \sqrt{\mathrm{in}}$ units, we get $\mathrm{K}_{\mathrm{IC}}=134 \mathrm{ksi} \sqrt{\mathrm{in}}$ and $\mathrm{J}_{\mathrm{IC}}=108$ $\mathrm{kJ} / \mathrm{m}^{2}$. It should be noted that the $\mathrm{K}_{\mathrm{IC}}$ in Table 1 for the $304 \mathrm{SS}$ is an experimentally obtained value.

Material properties (yield, tensile, and flow strengths, and Young's modulus) are given in Table 2 below.

Table 2 - Material Properties of Type 304 SS and A-193 Gr B7

\begin{tabular}{|l|l|l|l|l|l|l|}
\hline Material & $\begin{array}{l}\text { Temp. } \\
\left({ }^{\circ} \mathrm{F}\right)\end{array}$ & $\begin{array}{l}\text { Design } \\
\text { Stress } \\
\text { Intensity } \\
\text { Sm (ksi) }\end{array}$ & $\begin{array}{l}\text { Yield } \\
\text { Strength } \\
\text { Sy (ksi) }\end{array}$ & $\begin{array}{l}\text { Tensile } \\
\text { Strength } \\
\text { Su (ksi) }\end{array}$ & $\begin{array}{l}\text { Young's } \\
\text { Modulus } \\
\text { E (psi) }\end{array}$ & $\begin{array}{l}\text { Flow } \\
\text { Stress } \\
(\mathrm{ksi})\end{array}$ \\
\hline Type 304 & $\begin{array}{l}70 \text { to } 100 \\
\text { Gr CF8 }\end{array}$ & 20 & 30 & 70 & $28.3 \times 10^{6}$ & $60(\dagger)$ \\
\hline A-193 & 706 & 20 & 25 & 66.35 & $27.61 \times 10^{6}$ & 60 \\
Gr B7 & $\begin{array}{l}70100 \\
196\end{array}$ & 35 & 105 & 125 & $29.7 \times 10^{6}$ & 115 \\
$29.0 \times 10^{6}$ & $108(+\dagger)$ \\
\hline
\end{tabular}

(Reference 1, Tables 2A, 4, Y1, U and TM1)

$(\dagger) \quad$ The flow stress is given as $3 \mathrm{Sm}$ as suggested in Reference 9.

$(\dagger+)$ The flow stress is taken as $(\mathrm{Sy}+\mathrm{Su}) / 2$. A value of $105 \mathrm{ksi}$ is used in the analysis.

$(\dagger+\dagger)$ Tensile strength at $196^{\circ} \mathrm{F}$ is obtained by extrapolation as explained below.

The tensile strength of material A-193 Gr B7 at $196^{\circ} \mathrm{F}$ is not available in the literature (Ref.1). Therefore, the tensile strength was calculated approximately on the basis of material yield strength values at $100^{\circ} \mathrm{F}$ and $196^{\circ} \mathrm{F}$ and given tensile strength at $100^{\circ} \mathrm{F}$. 


\subsection{LOADING CONDITIONS}

\subsection{Temperature and Pressure}

The Bingham pumps operate at $196^{\circ} \mathrm{F}$ maximum at $100 \%$ of historic power (Ref. 10). Inlet and outlet pressures are 16 and $225 \mathrm{psig}$, respectively. Maximum pressure of $267 \pm 4$ psig occurs during start-up of the pumps' AC motor before opening the rotovalves for approximately $6 \pm 3$ seconds (Ref. 11). This pressure is rounded to $300 \mathrm{psig}$ for analysis purposes. However, for the suction cover bolt analysis, pressures ranging from 300 to 900 psig will be used to evaluate structural integrity of the bolts.

\subsection{Applied Loads}

The Bingham pumps are subjected to gravity, pressure, and seismic loadings due to their own geometrical configuration. In addition, the pumps are subjected to the piping loads at suction and discharge nozzles. The pump bearings are also exerted by thrust loading due to reactor coolant leakage around the impeller rims. However, the bearings do not form a part of the primary coolant pressure boundary and, therefore, no axial thrust will be considered in this analysis. Fluid transient loads have not been found to be significant in the process water system and, therefore, no such loads are included in this analysis. Thermal loads are considered insignificant due to low operating temperatures and lack of thermal gradients.

\subsection{FINITE ELEMENT MODEL AND FRACTURE ANALYSIS}

\subsection{Overview}

A finite element model of the Bingham pump is constructed for analyzing the pump response to the various static and seismic loadings. These loadings include process water pressure, pump weight, and piping reaction loads including seismic loading due to $0.2 \mathrm{~g}$ Safe Shutdown Earthquake (SSE). The three dimensional model can accommodate different pressures and nozzle loads. Since the membrane stresses are small (about $36 \%$ of the yield) for the pump casing, a simplified fracture analysis using Failure Assessment Diagram (FAD) methodology is used to assess the stability of a postulated flaw in the highly stressed region. A throughwall flaw is postulated for the pump casing. ASME Section XI, Code Case N-481 (Ref. 2) requires that a flaw one quarter throughwall and length six times its depth should be postulated. However, due to the highly localized nature of the stresses in the pump casing, the crack is expected to propagate through the wall first and then axially. Therefore, a conservative throughwall crack is postulated for the flaw analysis. For the suction cover, the main concern is the integrity of the $1-3 / 4$ " bolts that hold the cover against the pump casing. The bolts are analyzed for cracks using Crack Tip Opening Displacement (CTOD) criterion.

\subsection{Finite Element (FE) Model}

\subsubsection{Pump Casing}

The pump casing is a complex cast geometry with internal flow passages and flow splitters. Since the purpose of the analysis was to develop an acceptance criteria for the pump casing (and suction cover), deleting flow passages and splitter from the FE model will not adversely affect the analysis results. In fact, these flow passages and splitters act as stiffeners and, therefore, the model is expected to give conservative results.

The basic dimensions for generating the FE model were taken from drawings given in BPF 209325 (Ref. 6). To simplify the FE model, the suction cover was modeled separately. The shaft openings and suction cover end were modeled as closed ends of a pressure vessel. This simplification also 
will give conservative stresses. A review of the various drawings shows that the casing wall thickness varies from 1.25" to $1.75^{\prime \prime}$ and, therefore, a minimum wall thickness of 1.25 " was assumed for the entire model. The two chambers of the discharge volute are modeled as one volute without the splitter. The discharge volute is joined with the suction part of the casing of the pump by fillets to approximate the geometry and reduce stress concentrations.

The casing is modeled with shell elements (Type S4R5, S4R, and STRI35) in ABAQUS FE Code (Ref. 12) with the outer pump dimensions as median surface. This is done to simplify the casing measurements from the drawings, and additionally, this will give higher stresses (conservative) in the casing. The suction and discharge flanges were modeled as thick shells using ABAQUS Type S4R shell elements. The discharge nozzle up to the point (crotch) where it meets the casing is also) modeled with thick elements.

The model was generated with PATRAN (Ref. 13) FE preprocessor. The PATRAN model was translated to a FE mesh for the ABAQUS code on the SRS Cray X-MP EA Supercomputer.

\subsubsection{Suction Cover}

The suction cover is a cast stainless steel component with internal passages that direct the inlet flow to the suction of the impeller. The main concern in the structural integrity evaluation of the suction cover is the effect of bolt failures on the stability of the bolted joint between the cover and the rest of the pump casing. Therefore, the FE modeling was simplified and only those surfaces where high and low pressures act to transfer the load to the bolts are modeled. The bolts are modeled as beam elements (ABAQUS Type B31). These elements are joined with shell elements using Multi Point - Constraint (MPC - Type 7) feature in the ABAQUS code.

\subsection{Finite Element (FE) Mesh}

\subsubsection{Pump Casing}

Figure 1 shows the finite element (FE) mesh of the pump casing. The FE mesh contains 1400 thin shell elements for most of the model. There are 128 thick shell elements for the discharge nozzle and the two flanges. A total of 1536 nodes were used in the model. Two additional nodes were created at the center of the suction and discharge flanges so that the MPC option in the ABAQUS can provide rigid connections between these extra nodes and the pipe flange nodes. This ensures that all the nodes connected to the process water piping system will deform in a consistent manner.

\subsubsection{Suction Cover}

Figure 2 shows the finite element (FE) mesh of the pump suction cover. The FE mesh contains 1156 thin shell elements and 288 thick shell elements. There are 24 round beam elements for the suction cover bolts. A total of 1511 nodes were used in the model.

\subsection{Material Idealization}

The material of construction for the pump casing and the suction cover is Type 304 CF8 stainless steel. At $196^{\circ} \mathrm{F}$, Young's modulus is $27.61 \times 10^{6} \mathrm{psi}$. This material is assumed to behave with elastic - perfectly plastic (nonhardening) response with effective yield stress equal to the flow stress of the material. The flow stress was taken equal to 3 times $\mathrm{Sm}(60.0 \mathrm{ksi})$. The material for the suction cover bolts is the high strength material A-193 Gr B7. This material is also assumed to behave with elastic - perfectly plastic (nonhardening) response with effective yield stress equal to $108 \mathrm{ksi}$ as shown in Table 2 . A conservative value of $105 \mathrm{ksi}$ is used in the analysis to account for 
uncertainty in calculating tensile strength of bolt material at $196^{\circ} \mathrm{F}$. The Poisson's ratio is 0.3 for both materials.

\subsection{Boundary Condition}

The PWS pressure is assumed 300 psig. The piping loads are applied at the two node points at the center of the inlet and outlet flanges. The pump casing is anchored to the four pedestals through 1" thick plates which are welded to the pump casing at eight (8) different locations. The nodes at these locations of the pump casing are assumed to be fixed in all six degrees of freedom.

The piping nozzle loads are combined conservatively as Gravity+Thermal \pm Seismic loads. Maximum loads from all six loops were used in the analysis. Loop No. 4 (Ref. 14) was found to have the highest resultant forces and moments at the pump nozzles. Axial tensions due to $300 \mathrm{psig}$ pressure loading at the discharge nozzle and due to 16 psig pressure at the suction nozzle were also considered. This axial loading was combined absolutely with axial piping reaction forces for application at the pump nozzles.

\subsection{Pump Casing Analysis}

\subsubsection{Pump Frequency}

Pump natural frequency modes of vibration were calculated to determine if the pump casing had frequencies in the frequency range of SRS seismic response spectra. An allowance was made for the mass of water, impeller, shaft, and attached inlet and outlet piping. The additional mass was based on the Brookhaven National Laboratory estimate in their analysis of the pumps (Ref. 3). It is found that the additional mass is approximately $136 \%$ of the mass of the casing alone. The additional mass was added to the casing uniformly to calculate the first three modes of vibrations. The modal frequencies are given in the Table 3 below. The ABAQUS run output is given in Item 1 of Appendix A.

Table 3 - Bingham Pump Natural Frequencies

\begin{tabular}{|c|c|}
\hline Mode Number & $\begin{array}{c}\text { Frequency } \\
(\mathbf{H z})\end{array}$ \\
\hline 1 & 122 \\
\hline 2 & 146 \\
\hline 3 & 161 \\
\hline
\end{tabular}

The first mode frequency is sufficiently higher than the zero period acceleration frequency of 25-30) $\mathrm{Hz}$ for the SRS seismic response spectra (Ref. 15). Therefore, no seismic excitation is expected in the pump casing due to an SSE event at SRS.

\subsubsection{Pump Casing Stress Code Check}

The pump casing is subjected to a combined loading of gravity, pressure, and nozzle loads. Since the pump casing is rigid to seismic excitation, no dynamic analysis is performed. However, the piping loads applied at the suction and discharge nozzles do include piping seismic loads. A review of the detailed stresses output in Items 2 and 3 of Appendix A shows that there is considerable bending across the thickness of the casing at highly stressed points in the discharge volute. This is due to the sudden change in the pressure loading at the junction of suction and discharge volutes and abrupt changes in the geometry at this location. However, the discharge volute has a built-in splitter which will reduce these stresses (the splitter is not coded in the FE model for simplicity). It 
is also found that the effect of the nozzle loads is negligible. The maximum principal stresses due to pressure are similar, $18 \mathrm{ksi}$, to the case of combined loading and occur at the same location in the discharge volute. The nozzle loads are absorbed by the anchor points on the suction and discharge parts of the pump casing. The maximum principal stress distribution is shown in Figure 31 .

The maximum stress intensity S defined in the Article NB-3215 of the ASME Code (Ref. 1) is calculated from the three principal stresses $\sigma_{1}, \sigma_{2}$, and $\sigma_{3}$. These stresses are given in the ABAQUS run referenced in Item 3 of Appendix A. These $\sigma_{1}, \sigma_{2}$, and $\sigma_{3}$ are then combined to cbtain $S_{12}, S_{23}$, and $S_{31}$ as follows:

$$
S_{12}=\sigma_{1}-\sigma_{2} ; S_{23}=\sigma_{2}-\sigma_{3} ; \text { and } S_{31}=\sigma_{3}-\sigma_{1}
$$

The value of $S$ is the maximum of $S_{12}, S_{23}$, and $S_{31}$. These operations are summarized in Table 4 .

Table 4 - Calculation of Maximum Stress Intensity

\begin{tabular}{|c|c|c|c|c|c|c|c|}
\hline $\begin{array}{c}\text { Element } \\
\text { No. }(\dagger)\end{array}$ & $\begin{array}{c}\sigma_{1} \\
(\mathrm{ksi})\end{array}$ & $\begin{array}{c}\sigma_{2} \\
(\mathrm{ksi})\end{array}$ & $\begin{array}{c}\sigma_{3} \\
(\mathrm{ksi})\end{array}$ & $\begin{array}{c}S_{12} \\
(\mathrm{ksi})\end{array}$ & $\begin{array}{c}S_{23} \\
(\mathrm{ksi})\end{array}$ & $\begin{array}{c}S_{31} \\
(\mathrm{ksi})\end{array}$ & $\begin{array}{c}\mathrm{S} \\
(\mathrm{ksi})\end{array}$ \\
\hline 1047 & -21 & -7.78 & 0 & -13.2 & -7.78 & 21 & 21 \\
\hline 1047 & 0 & 6.24 & 15 & -6.24 & -8.76 & 15 & 15 \\
\hline
\end{tabular}

+ See $A B A Q U S$ run in Item 3 of the Appendix A. The two rows give the stresses at the inside and outside of the element number 1047.

The value $S$ includes local membrane $P_{L}$, and local bending stresses $Q$ described in the Table NB3217-1 (Ref.1). This classification of stresses is based on the fact that the stress distribution is local and through the thickness of the casing wall. The location of these stresses is close to the juncture of suction and discharge volutes. Let $P_{L}$ be the average of the maximum stress intensity, $S$. values through the thickness given above, then

$$
P_{L}=\frac{21+15}{2}=18 \mathrm{ksi}
$$

As indicated in Section 1.1, the pumps are built to manufacrurer's standards only and, therefore, the stress analysis is performed to meet the ASME Section III Code (Ref.1) stress limits. The following stress limits from Figure NB-3222-1 of the ASME Code apply for the applied loading during normal operating conditions.

$$
\mathrm{PL}=18 \leq 1.5 \mathrm{Sm}=30 \mathrm{ksi} ; \text { and } \quad \mathrm{Q}+\mathrm{PL}=21 \leq 3 \mathrm{Sm}=60 \mathrm{ksi}
$$

\subsubsection{Pump Casing Fracture Analysis}

Fracture analysis is performed using Failure Assessment Diagram (FAD) methodology (Ref. 23). FAD methodology covers the entire range from brittle failures to limit load failures. FAD methodology includes three categories of analyses. Category 1 analysis is based on linear elastic, plane strain fracture toughness $\mathrm{K}_{\mathrm{IC}}$. Category 2 and 3 analyses take advantage of increased material toughness due to ductile tearing for ductile materials. In general, Category 1 type of analysis gives conservative crack lengths and will be used here. Section 7.1 of Reference 23

1 Stress contours in Figure 3 are based on extrapolated stress values. Also, the numbers in the color bar should be extrapolated to the end of the bar for accurate estimate. 
indicates that Category 1 analyses can be used where failure is by ductile mechanism and no benefit is taken for the increased toughness due to ductile tearing.

The FAD methodology involves two steps. First, an FAD curve is constructed for the material in consideration. Second, a load application curve is drawn for various crack sizes. The intersection of the two curves gives the safe crack size.

The Category I FAD curve is based on the following relation (Ref.23).

$$
\begin{array}{ll}
K_{r}=\left(1-0.14 \times L_{r}^{2}\right)\left[0.3+0.7 \exp \left(-0.65 \times L_{r}^{6}\right)\right] & \text { for } L_{r} \leq L_{r}^{\max } \\
K_{r}=0 & \text { for } L_{r} \geq L_{r}^{\max }
\end{array}
$$

A value of $L_{r}^{\max }=1.8$ is suggested in Reference 23 for stainless steel.

$\mathrm{K}_{\mathrm{r}}$ and $\mathrm{L}_{\mathrm{r}}$ are defined as:

$$
\mathrm{K}_{\mathrm{r}}=\frac{\mathrm{K}_{\mathrm{I}}}{\mathrm{K}_{\mathrm{IC}}} \quad \text { and } \quad \mathrm{L}_{\mathrm{r}}=\frac{\text { Applied Load }}{\text { Limit Load }}=\frac{\mathrm{P}}{\mathrm{P}_{\mathrm{O}}}
$$

$K_{I}$ is calculated using the methodology given in Chapter 9 of Reference 16. In calculating $L_{r}, P$ is the applied pressure and $P_{O}$ is the limit pressure based on yield stress of the material. $P_{O}$ is calculated using the methodology given in Chapter 6 of Reference 16.

\section{Calculation of $\mathbf{K}_{\mathbf{I}}$}

A review of maximum principal stresses shows that the pressure is the dominant loading. The location of high stress lies in the doubly curved region of the discharge volute and appears to lie on the crown of the region (see Fig. 3). ASME Code Case N-481 (Ref. 2) recommends that a part throughwall crack should be postulated for fracture analysis. However, due to the highly localized nature of the maximum stress, a surface crack will propagate through the thickness before propagating axially. Therefore, an axial throughwall crack (Fig. 4) is postulated for the fracture analysis. A simplified method in Chapter 9 of Reference 16 is used to calculate the applied stress intensity factor. The following assumptions are made:

1. Doubly curved discharge volute is equivalent to an elbow of $16.75^{\prime \prime}$ diameter. This assumption is reasonable since the volute is circular (radius $=8.375^{\prime \prime}$ ) in geometry at the location of highest stress.

2. The postulated crack lies at the crown of the assumed elbow (Fig. 4).

3. The curvature of the volute is such that it satisfies the long radius elbow criterion of $R / D 0=$ 1.5 (Ref. 16). R and Do are shown in Figure 4. This assumption is reasonable since the radial distance of the centerline of the volute from the center of the pump is approximately 34.5". This will give $\mathrm{R} / \mathrm{Do}^{\prime}=2.1$. This is conservative for fracture analysis since the curvature of the volute is less than the long radius elbow with $\mathrm{R} / \mathrm{Do}=1.5$.

The stress intensity factor is calculated using the formula given in Chapter 9 of Reference 16. The formula is given below:

$$
\mathrm{K}_{\mathrm{I}}=\sigma \times(\pi \mathrm{Do})^{0.5} \times \mathrm{F}
$$


where

$$
\begin{aligned}
& F=1.2198 \times \frac{c}{D o} \times\left(\frac{D o}{t}\right)^{0.36} \\
& \text { Do }=\text { outside diameter of the elbow }=16.75^{\prime \prime} \\
& t=\text { wall thickness }=1.25^{\prime \prime} \\
& c=\text { half length of the crack } \\
& \sigma=\text { stress in ksi (calculated below) }
\end{aligned}
$$

A review of the stresses at the chosen location of the crack shows that the stresses vary through the thickness of the casing. Such a stress distribution will drive a surface crack part through the wall until the stresses are such that the crack cannot propagate any further. However, since a throughwall crack is postulated for the analysis, only membrane stresses are used to analyze the throughwall crack stability. The Table 5 below gives the maximum tensile principal stresses that are used to calculate the maximum membrane stress.

Table 5 - Calculation of Membrane Stress

\begin{tabular}{|c|c|c|c|}
\hline $\begin{array}{c}\text { Element } \\
\text { Number }(\dagger)\end{array}$ & $\begin{array}{c}\text { Maximum Principal } \\
\text { Stress (outside) } \\
(\mathrm{ksi})\end{array}$ & $\begin{array}{c}\text { Maximum Principal } \\
\text { Stress (inside) } \\
(\mathrm{ksi})\end{array}$ & $\begin{array}{c}\text { Membrane } \\
\text { Stress } \\
(\mathrm{ksi})\end{array}$ \\
\hline 1031 & 18.132 & 0.074 & 9.103 \\
\hline
\end{tabular}

+ See $A B A Q U S$ run in Item 3 of the Appendix $A$.

The above formula for $\mathrm{K}_{\mathrm{I}}$ is applicable for the following conditions.

1. 90 -degree long-radius elbow, $\mathrm{R} / \mathrm{Do}=1.5$

2. $\quad 0.02<\mathrm{c} / \mathrm{Do} \leq 0.5$ and $15 \leq \mathrm{Do} / \mathrm{t} \leq 100$

Half crack length $\mathrm{c}$ will vary from zero to the stable crack length obtained by using $F A D$ methodology described above. Code Case N-481 (Ref.2) requires that a minimum $\mathrm{c}=6 * \mathrm{~V} 4 * 1 / 2=$ $0.9375 "$ be postulated. For this case,

$$
\frac{\mathrm{c}}{\mathrm{Do}}=\frac{0.9375}{16.75}=0.056 \quad \text { Within the applicable range }
$$

However, $\quad \frac{\text { Do }}{\mathrm{t}}=\frac{16.75}{1.25}=13.4<15 \quad$ Beyond the applicable range

Do/t value does not meet the applicability limits of the solution. However, the form factor $F$ is proportional to Do/t and a value of Do/t $=15$ will be conservative. The stress, $\sigma$, is taken considering a safety factor of 3 for normal operating conditions. ASME Code, Section XI, paragraph IWB- 3642 (Ref.17) requires that a safety factor of 3 be used for normal including upset and test conditions, and 1.5 for the emergency operating conditions while assessing acceptability of the flaws. Since the stresses due to pressure are dominant, normal operating mode gives the limiting crack size.

\section{Calculation of $\mathbf{L}_{\mathbf{r}}$}

A pipe configuration was used for limit load analysis since the postulated flaw location is similar to a pipe. The limit load solution is readily available for the pipe with an axial throughwall flaw (Chapter 6 of Ref.16). In addition, at limit load conditions the curvature effects are not significant. Furthermore, the stresses where the flaw is postulated are highly localized and, therefore, the double 
curvature effect will not significantly alter the conclusions. The following equations are used to calculate the limit load with an axial crack.

$$
P_{0}=\sigma_{y} \frac{(\mathrm{U} / \mathrm{R})}{M}
$$

where

$$
\begin{aligned}
& P_{O} \text { is the limit load for a pipe with crack size } 2 c \\
& \sigma_{y}=25 \mathrm{ksi} \text { is the yield stress of the material }{ }^{2} \\
& M=\left(1+1.2987 \lambda^{2}-0.026905 \lambda^{4}+5.3549 \times 10^{-4} \lambda^{6}\right)^{0.5} \\
& \left.\lambda=\frac{c}{\left(R_{t}\right)}\right)^{0.5} \quad \\
& R=8.375^{\prime \prime} \quad \text { (radius of the assumed pipe) } \\
& t=1.25^{\prime \prime} \quad \text { (thickness of the assumed pipe) }
\end{aligned}
$$

Applied load $P$ is calculated based on the stress $\sigma$ and is given as $P=\sigma \frac{t}{R}$. $L_{r}$ can now be calculated from $\mathrm{L}_{\mathrm{r}}=\mathrm{P} / \mathrm{P}_{\mathrm{O}}$.

The results of the FAD) analysis for half crack sizes, $\mathbf{c}$, from 0 " to 3" long are shown in Figure 5. The limiting crack size is determined by the intersection point of the Category 1 FAD curve and the applied $\mathrm{K}_{\mathrm{r}}$ and $\mathrm{L}_{r}$ curve. This occurs at $\mathrm{K}_{r}=0.28$. The stable flaw size can now be calculated as follows:

$$
\begin{aligned}
& \mathrm{K}_{\mathrm{r}}=\frac{\mathrm{K}_{\mathrm{I}}}{\mathrm{K}_{\mathrm{IC}}}=0.28 \\
& \mathrm{KI}_{\mathrm{I}}=0.28 * 230=64.4 \mathrm{ksi} \sqrt{\mathrm{in}}
\end{aligned}
$$

Using the $\mathrm{K}_{\mathrm{I}}$ on page 7 we can calculate the limiting flaw size. This gives a flaw size, $2 c$, equal to 3.5". This is a conservative estimate and a higher critical flaw size will be obtained if FAD Category 2 or 3 (Ref. 23) analyses when increased fracture toughness is used.

\subsection{Suction Cover Analysis}

The main purpose of the suction cover analysis was to assess the structural integrity of the 1-3/4" bolts. The loading on the suction cover is essentially pressure loading. The suction cover is acted on by low $\mathrm{D}_{2} \mathrm{O}$ pressure when it guides the inlet $\mathrm{D}_{2} \mathrm{O}$ into the impeller eye. The suction cover is also acted upon by the high pressure due to the leakage around the impeller rim. The weight loading and seismic loading are negligible. The maximum principal stress in the suction cover is approximately $13 \mathrm{ksi}$ (Fig. 6) at the design pressure of 300 psig. This is based on a thickness of $1.25 "$ all over the suction cover. In reality, the cover thickness is more than 1.25 " and, therefore, the stresses in the cover are not a concern.

The scenario examined here is the cracking of one or more bolts. The following analyses are performed to evaluate the bolt integrity.

1. With all bolts intact, maximum bolt deflections are obtained for high pressures ranging from 300 psig to 900 psig. The ABAQUS run output is given in Item 4 of Appendix A.

2 Reference 16 recommends using flow stress of the material to calculate the limit load, however. the FAD formulation is based on yield stress of the material. 
2. With all bolts cracked with a crack $25 \%$ deep through the diameter, maximum deflections are obtained for high pressures ranging from 300 psig to $900 \mathrm{psig}$. This analysis will show that even if all the bolts have flaws, the bolt stresses are well below the yield stress and, therefore, will not fail for the design pressure. The ABAQUS run output is given in Item 5 of Appendix A.

3. Next, the cracked bolts are removed in succession. This is done by using CHANGE MODEL option in ABAQUS. First, two highly loaded bolts are removed. (The suction cover model is not symmetric all around since the outboard bearing is bolted to the lower half of the suction cover. Figure 2 does not show that lower half). Then using the RESTART and CHANGE MODEL options in ABAQUS, the next two bolts are removed. A total of 8 bolts are removed in this manner to see if bolts will experience any yielding. The loss of 8 bolts (out of 24) will cause sufficient movement of the suction cover so as to cause $\mathrm{D}_{2} \mathrm{O}$ leak and the subsequent detection by the tritium monitoring equipment. However, the $\mathrm{O}$-ring between the suction cover and pump casing may prevent any significant leakage. The ABAQUS run output is given in Items 6 through 9 of Appendix A.

4. A fracture analysis using the Crack Tip Opening Displacement Criterion (CTOD) is performed for the bolts. This analysis will determine the number of cracked bolts that could be missing at various pressures without any additional bolt failures.

\subsubsection{Initial Bolt Tightening}

The bolts are initially torqued to $750 \mathrm{ft}-\mathrm{lbs}$ (Ref. 18) torque. This initial torque gives the following pretension (Ref. 19).

$$
F=\frac{5 \times M_{t}}{d}
$$

where

Mt is the initial torque in-lbs

$d$ is the nominal bolt diameter in inches

Therefore, $\quad F=\frac{5 \times 750 \times 12}{1.75}=25714 \mathrm{lbs}$

Axis! extension for this pretension is,

where

$$
\delta=\frac{\mathrm{FxL}}{\mathrm{AxE}}
$$

$\mathrm{F}$ is the pretension in lbs

$\mathrm{L}$ is the length of the bolt $=2.75^{\prime \prime}$

$A$ is the stress area of the bolt $=1.8983$ in $^{2}$

Therefore,

$$
\mathrm{E} \text { is the Young's modulus }=29 \times 10^{6} \mathrm{psi}
$$

$$
\begin{aligned}
& \delta=\frac{F x L}{A x E}=\frac{25714 \times 2.75}{1.8983 \times 29 \times 10^{6}} \\
& \delta=0.00128^{\prime \prime}
\end{aligned}
$$

Prestress due to initial torque $=\frac{F}{A}=\frac{25714}{1.8983}$

$$
=13546 \mathrm{psi}
$$


Since the most likely location of a crack is the minor diameter of the bolt thread, a crack $25 \%$ deep through the diameter will be assumed. In that case, the remaining cross sectional area $A_{r}(F i g .7)$ is given as,

$$
A_{r}=R^{2}\left(\pi-\cos ^{-1} \frac{R-a}{R}\right)+(R-a) \sqrt{R^{2}-(R-a)^{2}}
$$

Where

$$
\begin{aligned}
& \mathrm{R}=\text { minor radius of the uncracked bolt }=0.7523 " \\
& \mathrm{a}=\text { depth of the crack }=0.25 \times 2 \mathrm{R}=0.37615^{\prime \prime}
\end{aligned}
$$

Theiefore,

$$
\mathrm{A}_{\mathrm{r}}=1.43 \mathrm{in}^{2}
$$

Effective radius for the cracked bolt analysis $=\sqrt{\frac{1.43}{\pi}}=0.6748 \mathrm{in}$.

\subsubsection{Bolt Stress Analysis}

As indicated in Section 1.1, the pumps are built to manufacrurer's standards only and, therefore, the stress analysis is performed to meet the ASME Section III Code (Ref.1), paragraph NB-3230 requirements. The ASME Code requires that certain stress limits given in NB-3232.3(b) be satisfied and a fatigue analysis be performed. For the high strength bolting, the following stress limits should be satisfied

$$
\begin{aligned}
& \text { Maximum stress }=2.7 \mathrm{Sm}=2.7 \times 32.7=88.3 \mathrm{ksi} \\
& \text { Direct stress }=2.0 \mathrm{Sm}=2 \times 32.7=65.4 \mathrm{ksi}
\end{aligned}
$$

Where Sm is the stress intensity per Table 4 of Referencel. Sm $=32.7 \mathrm{ksi}$ at $196^{\circ} \mathrm{F}$.

The ABAQUS FE model gives stresses at the outer fiber of the bolt, however, we shall use the direct stress limit to evaluate these bolts. Furthermore, the prestress will be directly added to the ABAQUS calculated stress due to pressure loading. The Table 6 below gives the summary of the bolt stresses at design pressure equal to $300 \mathrm{psig}$.

\section{Table 6 - Suction Cover Bolt Stresses}

\begin{tabular}{|c|c|c|c|c|}
\hline Bolt Condition & $\begin{array}{c}\text { Prestress } \\
(\mathrm{ksi})\end{array}$ & $\begin{array}{c}\text { Pressure Stress } \\
(\mathrm{ksi})(\dagger)\end{array}$ & $\begin{array}{c}\text { Combined Stress } \\
(\mathrm{ksi})(\dagger)\end{array}$ & $\begin{array}{c}\text { Allowable Stress } \\
(\mathrm{ksi})\end{array}$ \\
\hline All Bolts Active & 13.55 & 17 & 30.55 & 65.4 \\
\hline 2 Bolts Inactive & 13.55 & 27 & 40.55 & 65.4 \\
\hline 4 Bolts Inactive & 13.55 & 50 & 63.55 & 65.4 \\
\hline 6 Bolts Inactive & 13.55 & 99 & 105.00 & 65.4 \\
\hline 8 Bolts Inactive & 13.55 & 105 & 105.00 & 65.4 \\
\hline
\end{tabular}

$(\dagger)$ Stresses are based on an equivalent area of a cracked bolt with an area $=1.43 \mathrm{in}^{2}$. The crack is $25 \%$ deep through the root or minor diameter of the bolt. Since the flow stress is $105 \mathrm{ksi}$, the bolt stresses are limited to $105 \mathrm{ksi}$. 
Based on this analysis, it is found that even if 4 bolts are inactive and all other bolts are cracked $25 \%$ deep through the minor diameter of the bolt, the structural integrity of the suction cover is not adversely affected.

\subsubsection{Bolt Fatigue Analysis}

Fatigue analysis is performed in accordance with NB 3222.4 (Ref.1). Fatigue evaluation shall be performed for the conditions in which all the bolts are cracked $25 \%$ deep through the minor diameter but are all active. This is reasonable since the fatigue analysis is based on lifetime operation, and any broken bolts will be replaced during in-service inspections. The iatigue analysis procedure is given in NB-3222.4(e) (Ref.1).

Since the stress fluctuations occur about the prestress, prestress is not included in the calculations for alternating stress.

Therefore, $\quad$ Maximum stress, $\mathrm{S}_{\max }=17+13.55=30.55 \mathrm{ksi}$. Minimum stress, $S_{\min }=13.55 \mathrm{ksi}$

Fatigue strength reduction factor per NB-3232.3(c) $=4$

Therefore, alternating stress intensity, $\mathrm{Sa}=\frac{S_{\max }-S_{\min }}{2} \times \frac{30}{29} \times 4$

$$
=\frac{17 \times 30 \times 4}{2 \times 29}=35.17 \mathrm{ksi}
$$

The factor 30/29 is the correction due to Young's moduli difference between the fatigue curve and the actual material value. Using the design fatigue curves in Fig. I-9.4 of Reference 1, we get the maximum number of cycles equal to 9000 for the alternating stress intensity of $35.17 \mathrm{ksi}$. This is the number of cycles that the pumps can be started and shutdown without causing any additional fatigue damage to the cracked bolts.

\subsubsection{Bolt Fracture Analysis}

Figure 7 shows the cracked bolt model for the fracture analysis. Fracture analysis of the bolts is based on the CTOD criterion. The analysis follows the methodology used in Reference 21 . A "strip yield model" or Dugdale crack model leads to $\mathrm{J}=\sigma_{\mathrm{f}} \delta_{\mathrm{t}}$, where $\mathrm{J}$ is the fracture parameter $\mathrm{J}$ integral, $\delta_{\mathrm{t}}$ is the crack tip opening displacement, and $\sigma_{\mathrm{f}}$ is the flow stress used for the bolt material. The fracture condition $J=J_{I C}$ is met when $\delta_{t}=\delta_{t}$ critical $=C T O D$. In Section 2.1, $\mathrm{J}_{I C}$ is given as $108 \mathrm{~kJ} / \mathrm{m} 2$ or $618.0 \mathrm{lb} / \mathrm{in}$. Therefore, the critical tip opening displacement (CTOD) is $\frac{\mathrm{J}_{\mathrm{IC}}}{\sigma_{\mathrm{f}}}=0.006^{\prime \prime}$ for $\sigma_{\mathrm{f}}=105 \mathrm{ksi}$ (see Table 2). Assuming that the bolts are rigid up to plastic collapse, the critical bolt extension will be equal to CTOD.

Figure 8 gives the bolt deflections for pressures ranging from 0 psig to $900 \mathrm{psig}$. The deflections include the initial extension $(0.00128$ ") due to pretension. The bolt deflections are given for all the cases described in the beginning of Section 4.7. The inset in the Figure 8 is an exploded view for small bolt deflections. From the pressure vs. bolt deflection curves in Figure 8, it can be seen that the critical pressure level corresponding to this critical displacement, CTOD, is approximately 275 psig for the bolt configuration with zero, two, four, and six inactive bolts. Conversely, when all bolts contain $25 \%$ deep flaws, the pump can be safely operated at a maximum operating pressure of 271 psig (including the pump starting transient mentioned in Section 3.1) for the cover with 0,2,4. or 6 nonfunctional bolts (without fracturing additional bolts). 


\subsection{ACCEPTANCE CRITERIA METHODOLOGY FOR THE BINGHAM PUMPS}

\subsection{Basis for In-Service Inspection}

No leakage failures have occurred in the Bingham pump casings or the suction covers throughout their service history. No service-induced degradation is predicted for the pump casing, suction cover, and suction cover bolting. Examinations (with visual, surface, or volumetric methods), conducted under an in-service inspection program, provide specific information on the condition of the component throughout service to support the structural integrity demonstration. An acceptance criteria methodology is a framework for periodically monitoring the service condition through inservice examinations and includes the disposition of degraded conditions while maintaining safety margins against failure.

An acceptance criteria methodology is proposed for the pressure boundary components of the Bingham pumps to meet the safety margins against failure stated in Sections 4.6.3, and 4.7.2 and ir.volves the following sequence in an in-service inspection program: 1) Baseline Examination; 2) Evaluation; 3) Acceptance; and 4) Successive Examinations.

Additional details on the acceptance criteria methodology are discussed in Section 5.2. The disposition of flaws is discussed in Section 5.3. The development of programmatic requirements as part of an in-service inspection plan for the in-service examinations of the pumps is outside the scope of this report.

\subsection{Acceptance Criteria Methodology}

The acceptance criteria methodology includes monitoring through periodic examinations (with visual, surface, or volumetric methods) to demonstrate that the components meet the stated safety margins against failures. The fracture analysis results in this report meet the ASME Code Case N481 (Ref.2) requirements which exempt pump casing welds from volumetric examination. However, if a volumetric examination is performed, this report provides the technical bases for accepting or dispositioning an indication (Section 4). Periodic surface and/or volumetric examinations for the suction cover bolting would provide assurance of bolt integrity through service.

Baseline examinations of the pump components would be performed in accordance with the code case for In-Service Inspection for Low Temperature Heavy Water Reactors, presently in draft (Ref.22). Evaluation and acceptance of degradation would include comparison of the conditions with the acceptance standards for the pump components provided in the code case. For example, if a reported flaw size exceeds the allowable sizes in the acceptance standards, then acceptance-byanalysis and/or additional examinations would be required for acceptance of the condition (see Section 5.3).

Periodic monitoring through successive examinations would be continued with an increase in the frequency of examinations, if degradation is significant (see Section 5.3).

\subsection{Disposition of Flaws}

Acceptance standards for flaws reported in the in-service inspection of the pump pressure boundary components are provided in the code case for Low Temperature Heavy Water Reactors, presently in draft (Ref.22). If a relevant indication does not exceed the allowable flaw size specified in the acceptance standards, no further evaluation would be necessary and examination of the component would be performed at the next interval in the inspection program. If a flaw exceeds the size in the acceptance standards, acceptance-by-analysis and/or additional examinations would be required per 
the code case for acceptance of the flaw. Evaluation of the service-induced degradation and the flaw growth rate would be performed, and, if a flaw is predicted to exceed the acceptance criteria (Section 4) prior to the next interval in the inspection program, then the flaw would be re-inspected before the next interval such that the acceptance criteria are met. The flaw growth rate evaluation would be updated following each successive examination or reexamination.

The acceptance criteria provided in Section 4 are the acceptable tlaw sizes to maintain the defined safety margins for the pump casing and suction cover bolts. No flaws in these components of the pumps shall exceed or be predicted to exceed these configurations. Flaws in these components that exceed or are predicted to grow to exceed the acceptable configurations while in service would require repair or replacement of the pump components.

\subsection{CONCLUSIONS}

1) The analysis shows that the maximum stresses in the pump casing meet the stress limits given in the ASME Code. Therefore, the structural integrity of the pump casing is ensured.

2) The fracture analysis of the pump casing shows that the critical crack length for a throughwall crack is $3.5^{\prime \prime}$ with a safety margin of 3 . This size crack is easily detectable during in-service inspection and, therefore, the current inspection practice of visual examination is adequate. The fracture analysis meets the ASME Code Case N-481 requirements and, therefore, volumetric examination of the casing welds is not necessary.

3) Suction cover bolt analysis shows that for the design conditions, up to 4 bolts could be broken without causing any further loss of suction cover bolting. Therefore, the current inspection practice of visual and volumetric examinations of the bolting is adequate. 


\subsection{REFRENCES}

1) ASME Boiler and Pressure Vessel Code, Sections II (Part D), and III, Edition 1992.

2) ASME Boiler and Pressure Vessel Code Section XI, Code Case N-481, 1990

3) Bingham Pump Evaluation, Brookhaven National Laboratory, January 1990 (No document number is given on the document).

4) Hartman, E.R., et al., "Reactor Materials Program: LBB Assessment - Flanges, Valves and Pumps", DPST-88-404, E.I. du Pont de Nemours \& Co., Aiken, SC, March 1988.

5) DPSOL 105 - 1851B - PLK, Periodic Equipment Inspections - Schedule.

6) BPF No. 209325, Drawings: Z-2631; E-5480, Z-2613; Z-2622; B-7138 and B-7139; Z2667; Z-2678; and Engineering Data Sheet.

7) Stoner, K.J., et al., "Reactor Materials Program: Baseline Materials Handbook - Mechanical Properties of 1950's Vintage Stainless Steel Weldment Components (U)", WSRC-TR-9110. Westinghouse Savannah River Co., Aiken, SC, April 1991.

8) Elastic and Plastic Fracture, by Atkins and Y-W. Mai, Ellis Horwood Series, 1988.

9) Ranganath, S. and Mehta, H.S., "Engineering Methods for the Assessment of Ductile Fracture Margin in Nuclear Power Piping", in Elastic-Plastic Fracture: Second Symposium. Volume ПI. ASTM STP 803, C.F. Shih and J.P. Gudas, Eds., American Society tor Testing and Materials, 1983, pp. II-309 to 330.

10) Amin. D.A., "K-Reactor PWS Loop Piping System Load Report", Calc \# M-CLC-K00235, Westinghouse Savannah River Co., Aiken, SC, May 1992.

11) Whitehouse, J., "HX Inlet Pressure with Bingham Pump Dead-Headed", NES-ETH920039, Interoffice Memorandum, Westinghouse Savannah River Co., Aiken, SC, January 23, 1992.

12) ABAQUS, Version 4-9, Hibbitt, Karlsson, \& Sorensen, Inc., Pawtucket, Rhode Island, 1992.

13) PATRAN PLUS, Release 2.5. PDA Engineering, Costa Mesa. California, October 1990.

14) Log Book WSRC-NB-92-111, Structural Integrity Evaluation of Bingham Pumps, Westinghouse Savannah River Co., Aiken, SC, 1992.

15) Seismic Engineering Procedure, SEP-11, Westinghouse Savannah River Co., Aiken, SC.

16) Ductile Fracture Handbook, Vol. 2 Chapter 6, and Vol. 3 Chapter 9, Electric Power Research Institute NP-6301-D, January 1991.

17) ASME Boiler and Pressure Vessel Code, Section XI, Edition 1992.

18) DPSOL 1-10028, Rev 8, "Bingham Pump, Complete Overhaul". 
19) Practical Stress Analysis in Engineering Design, by Alexander Blake, Marcel Dekker, Inc., 1982.

20) Mark's Mechanical Engineers' Handbook, 6th Edition, McGraw Hill, Book Company, 1964.

21) Lam, P.S., Sindelar, R.L., and Barnes, D.M., Heat Exchanger Staybolt Acceptance Criteria (U), WSRC-TR-92-11, Westinghouse Savannah River Co., Aiken, SC, February 1992.

22) Cowfer, C.D., "Requirements for Inspection of Heavy Water Production Reactor (U)", WSRC-TR-90-42-141 Rev.0, Westinghouse Savannah Piver Co., Aiken, SC, May 1992 [initial draft of the code case being prepared by the ASME Section XI Special Working Group - Low Temperature Heavy Water Reactor].

23) Milne, I., Ainsworth, R.A., Dowling, A.R., and Stewart, A.T., Assessment of the Integrity of Structures Containing Defects, Int. J. Pressure Vessel \& Piping, 32 (1988), pp. 3-104. 

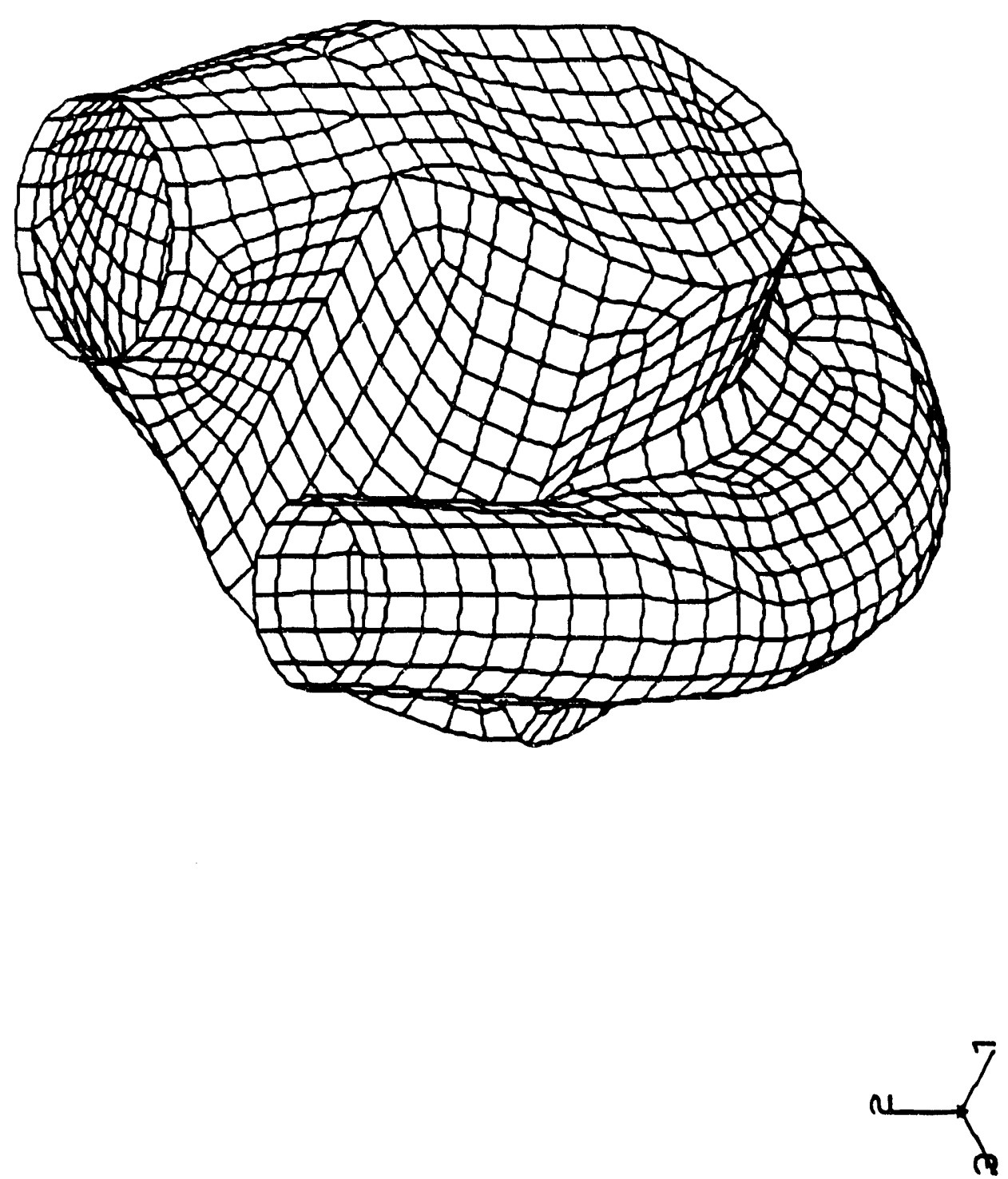

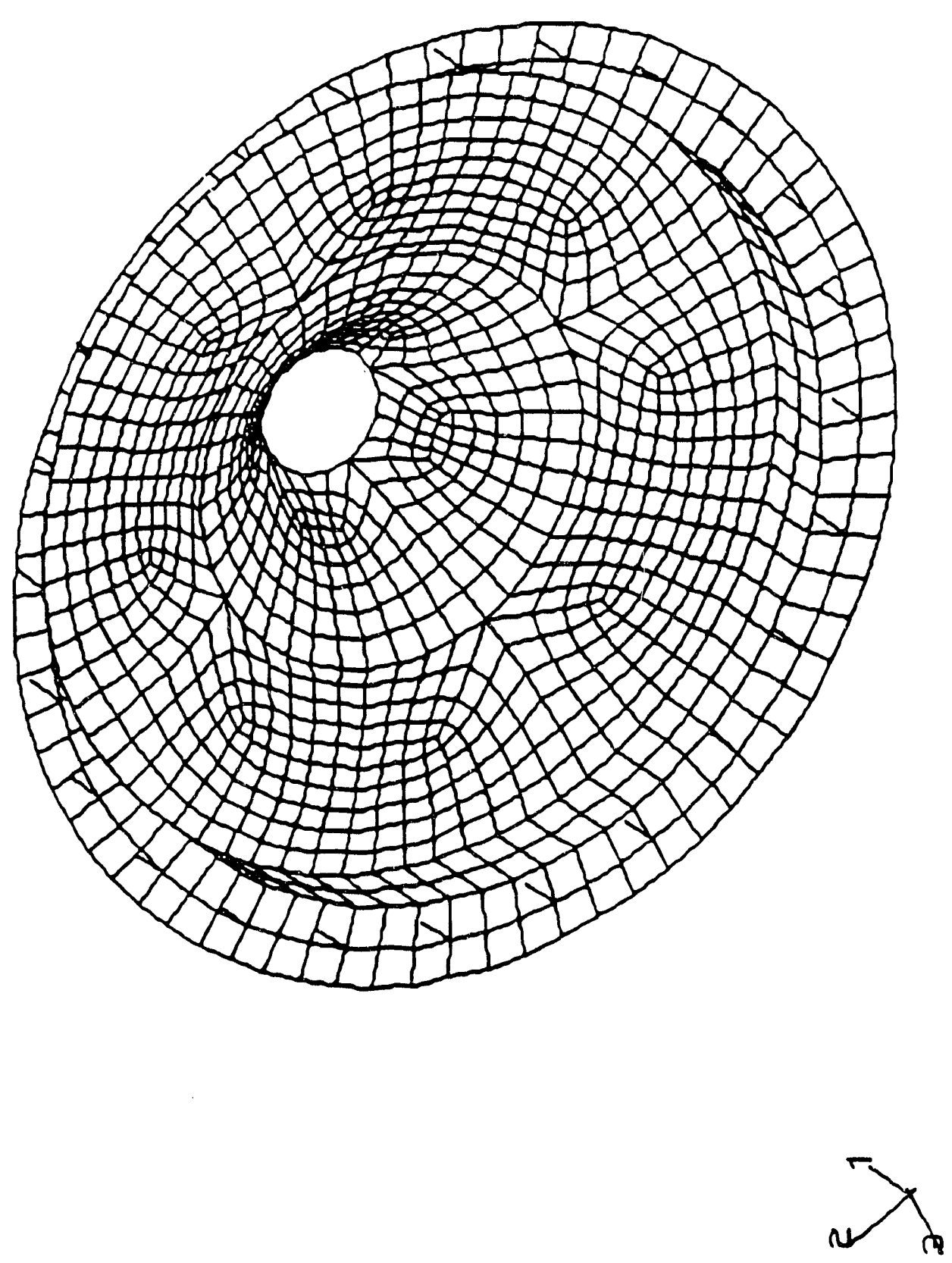
憂

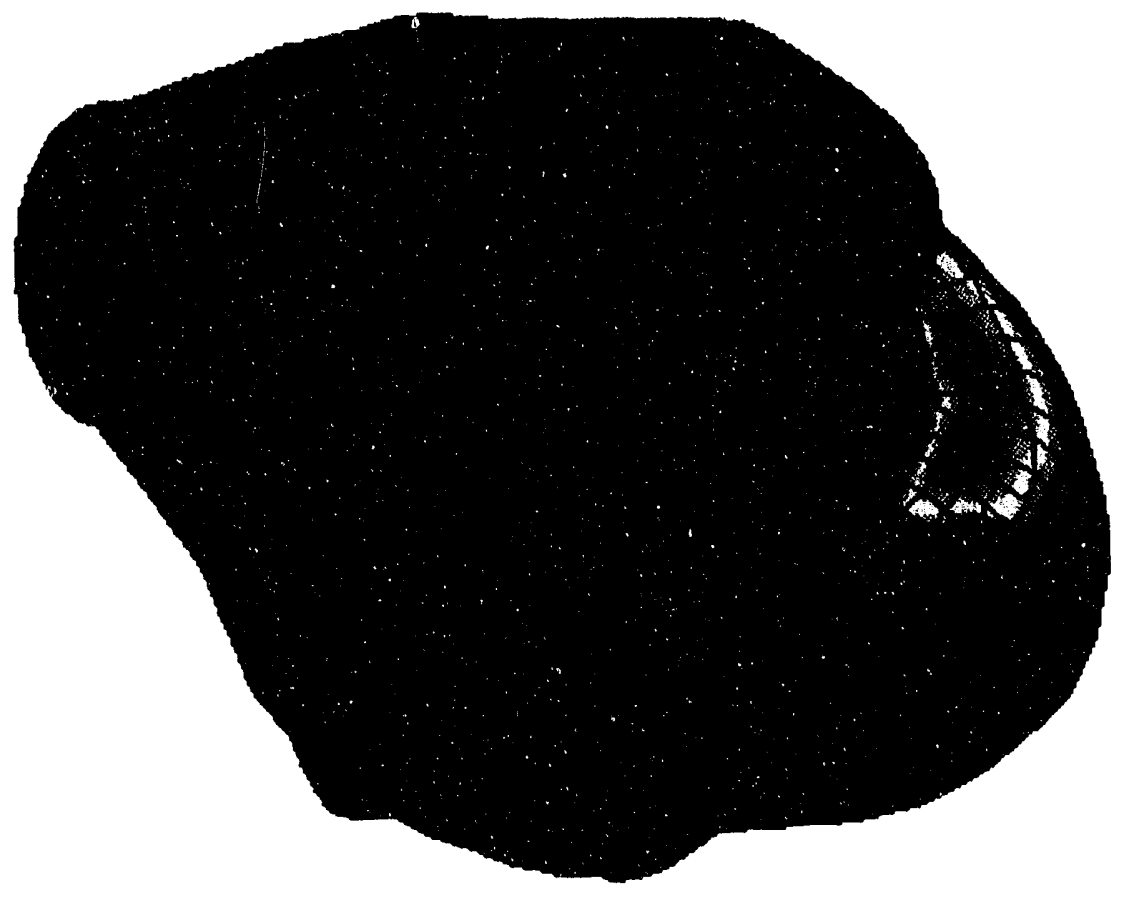

$\sum^{2}$

를

$z$

氠
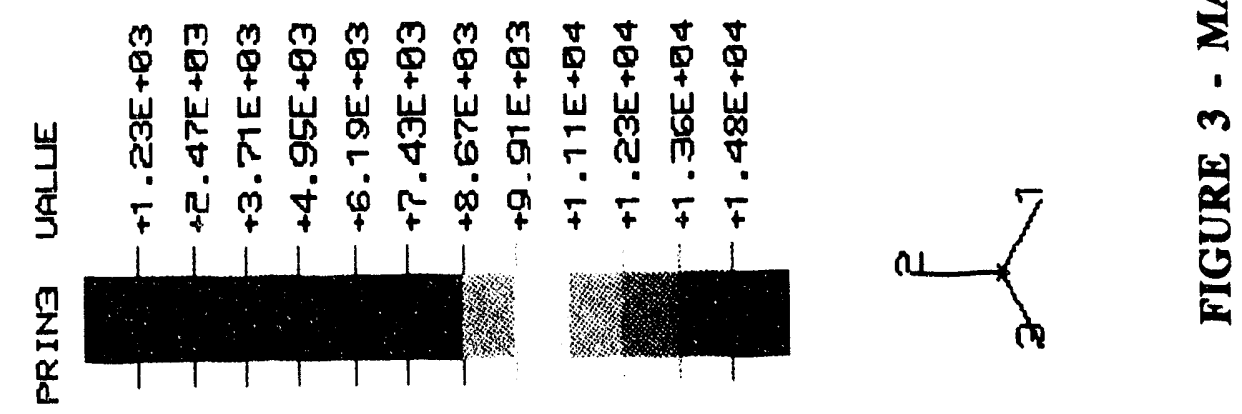

$\frac{2}{2}$ 
October 1992

Page 20 of 24
WSRC-TR-92-12

Task $91-086-1$

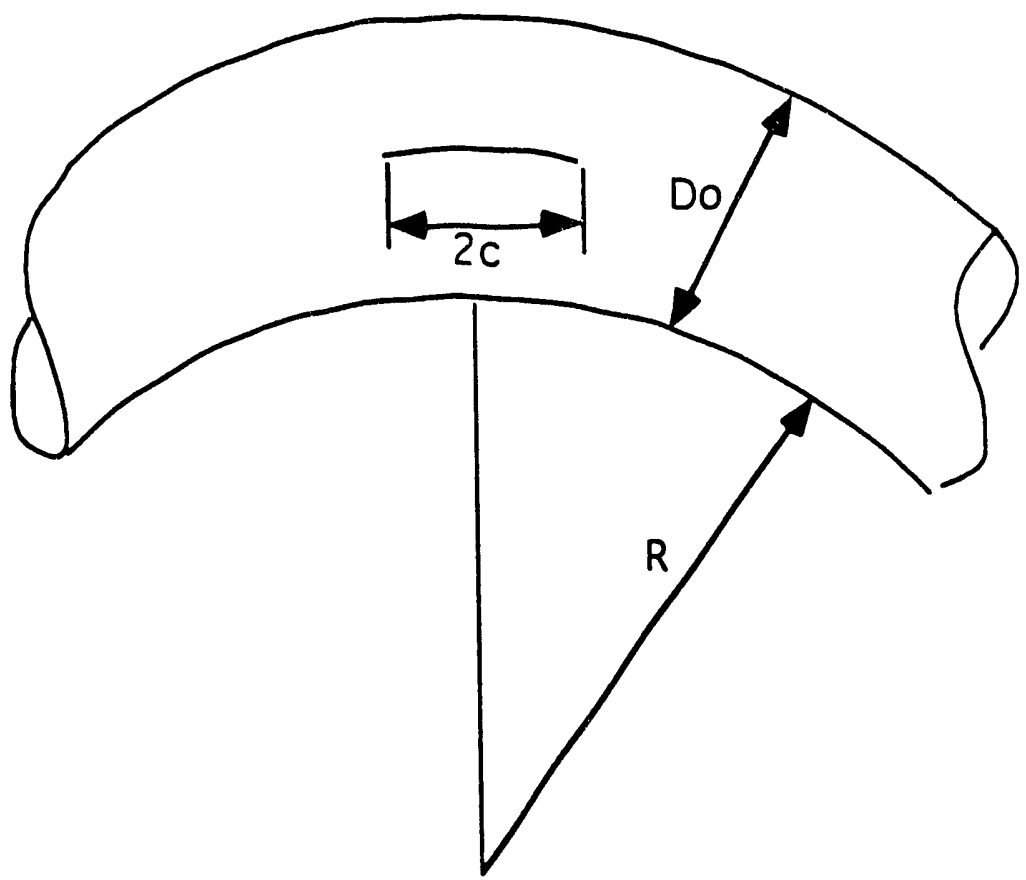

FIGURE 4 - DISCHARGE VOLUTE CRACK MODEL

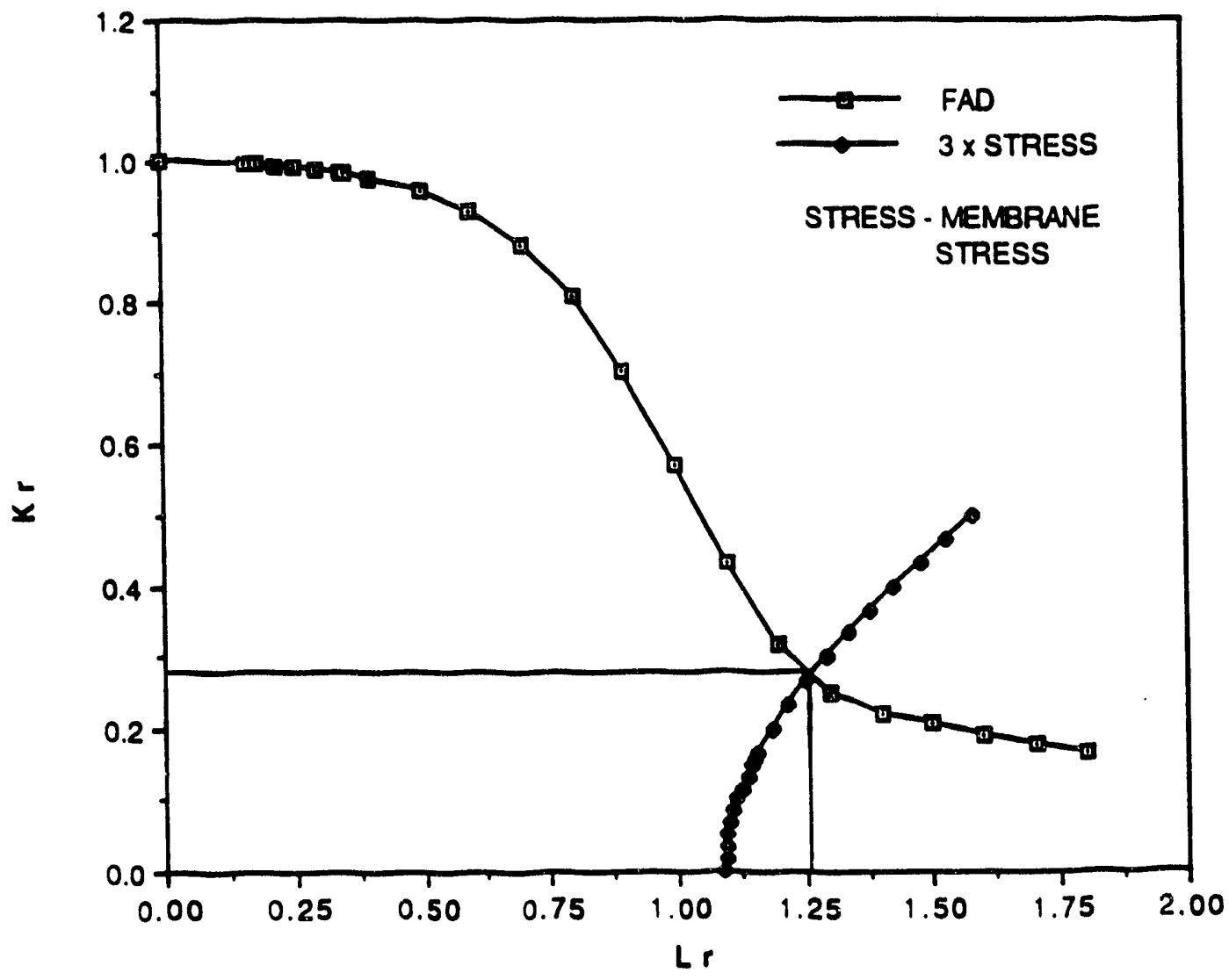

FIGURE 5 - FAILURE ASSESSMENT DIAGRAM 


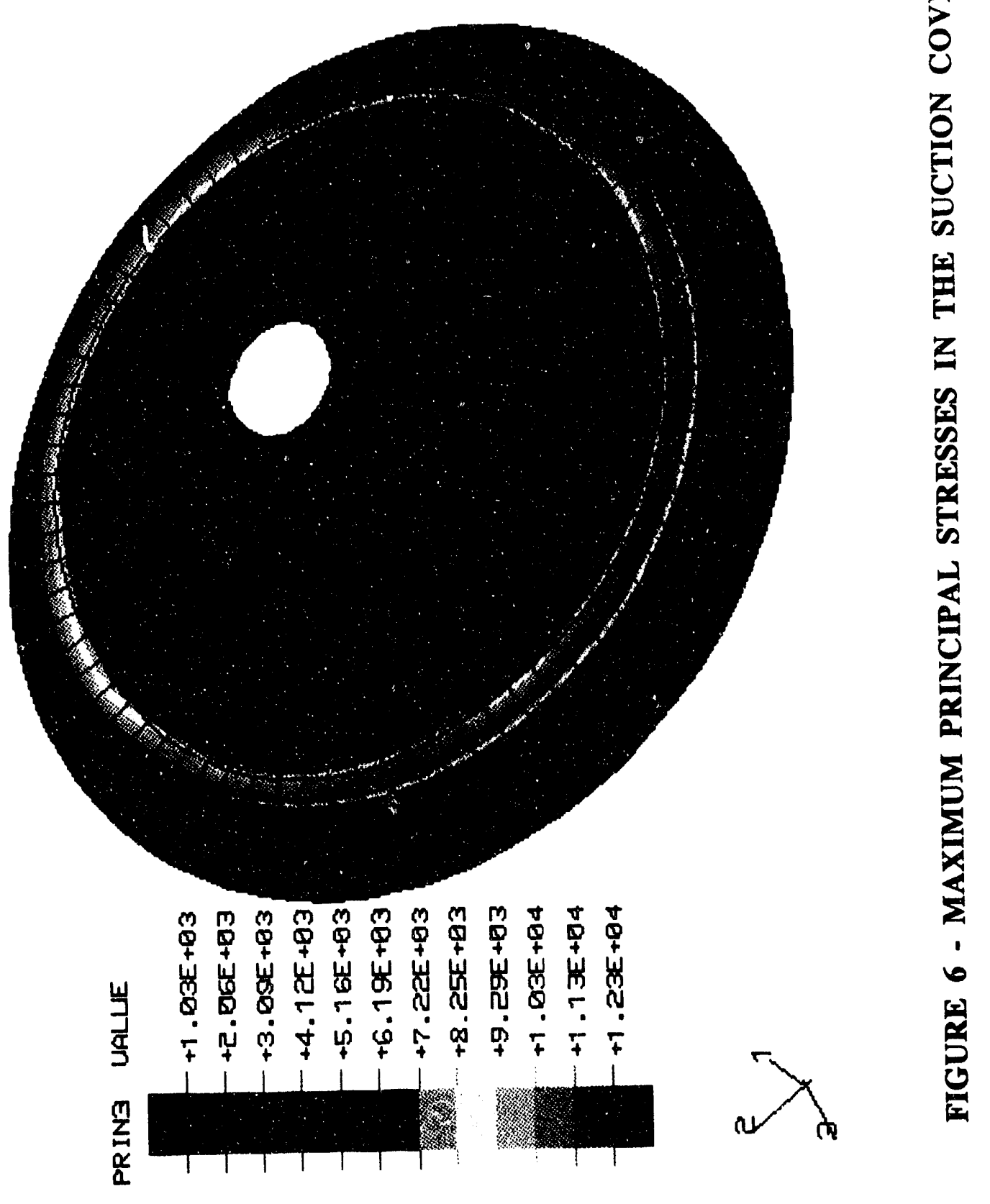




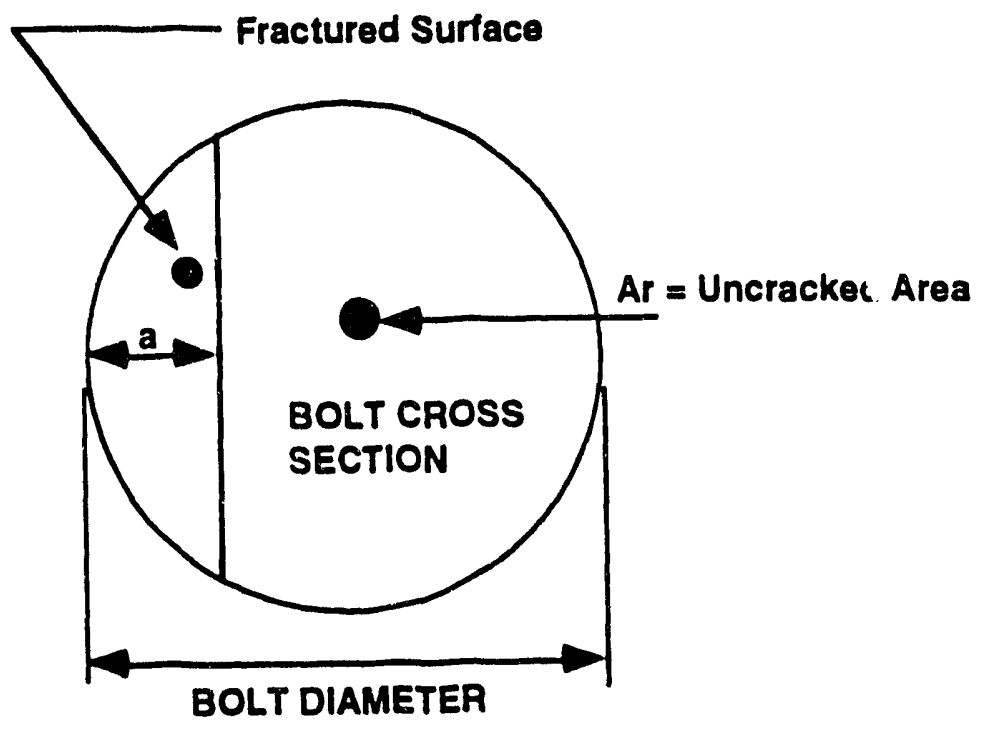

FIGURE 7 - SUCTION COVER BOLT CRACK MODEL 


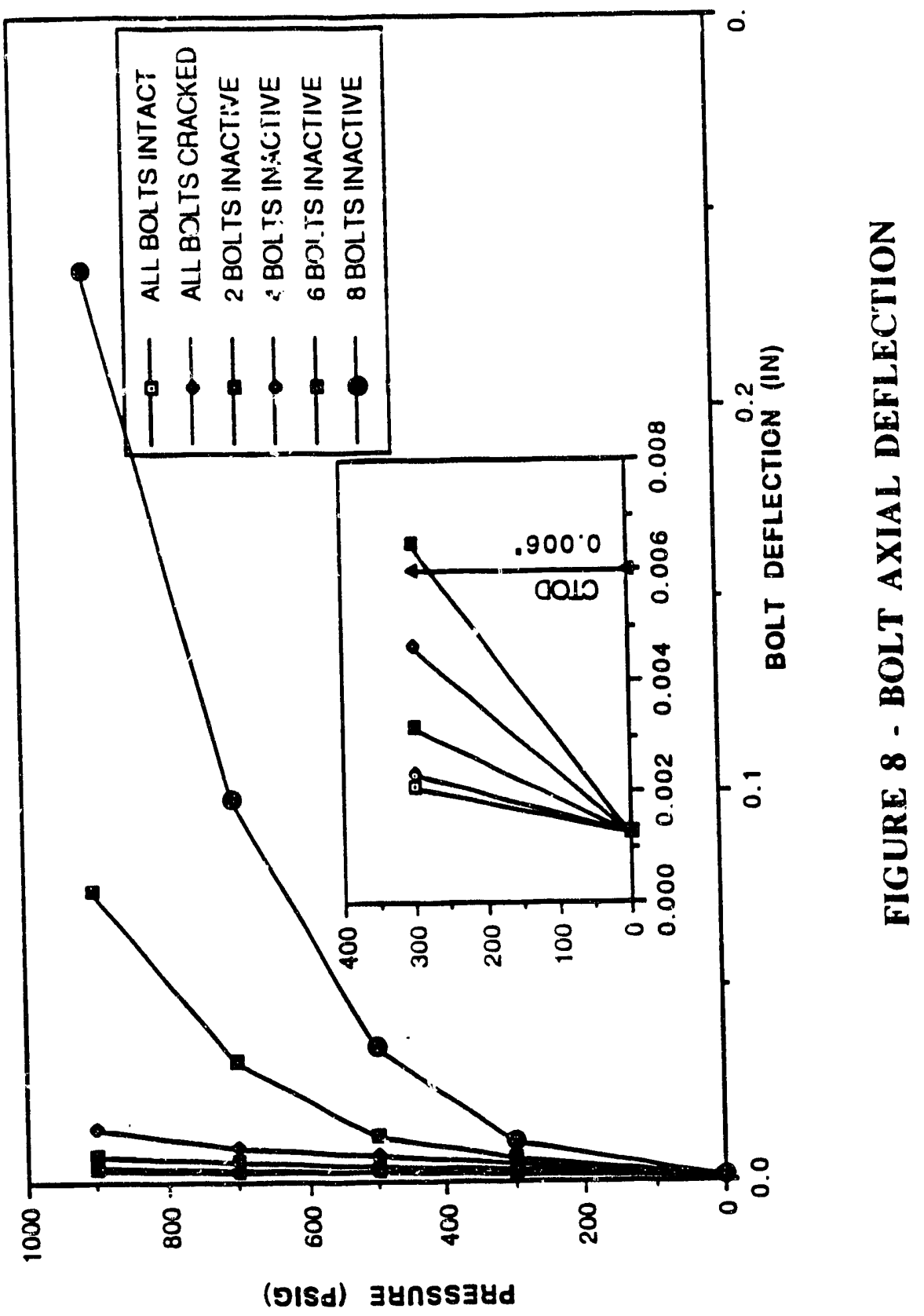


APPENDIX A

\section{TABLE OF ABAQUS COMPUTER RUNS}

\begin{tabular}{|c|c|c|l|}
\hline $\begin{array}{c}\text { Item } \\
\text { No. }\end{array}$ & $\begin{array}{c}\text { Output } \\
\text { (.DAT)File }\end{array}$ & $\begin{array}{c}\text { Restart } \\
\text { (.RES) File }\end{array}$ & \multicolumn{1}{|c|}{ File Description } \\
\hline 1 & pump_fre & pump_fre & Pump casing frequency analysis \\
\hline 2 & pump_pre & pump_pre & Pump casing analysis run with pressure load only \\
\hline 3 & pump_noz & pump_noz & $\begin{array}{l}\text { Pump casing analysis with pressure, gravity \& nozzle } \\
\text { loads }\end{array}$ \\
\hline 4 & cover & cover & Suction cover analysis with all bolts intact \\
\hline 5 & cover-c & cover-c & Suction cover analysis with all bolts cracked \\
\hline 6 & cover-c2 & cover-c2 & Suction cover analysis with all 2 cracked bolts inactive \\
\hline 7 & cover-c4 & cover-c4 & Suction cover analysis with all 4 cracked bolts inactive \\
\hline 8 & cover-c6 & cover-c6 & Suction cover analysis with all 6 cracked bolts inactive \\
\hline 9 & cover-c8 & cover-c8 & Suction cover analysis with all 8 cracked bolts inactive \\
\hline
\end{tabular}



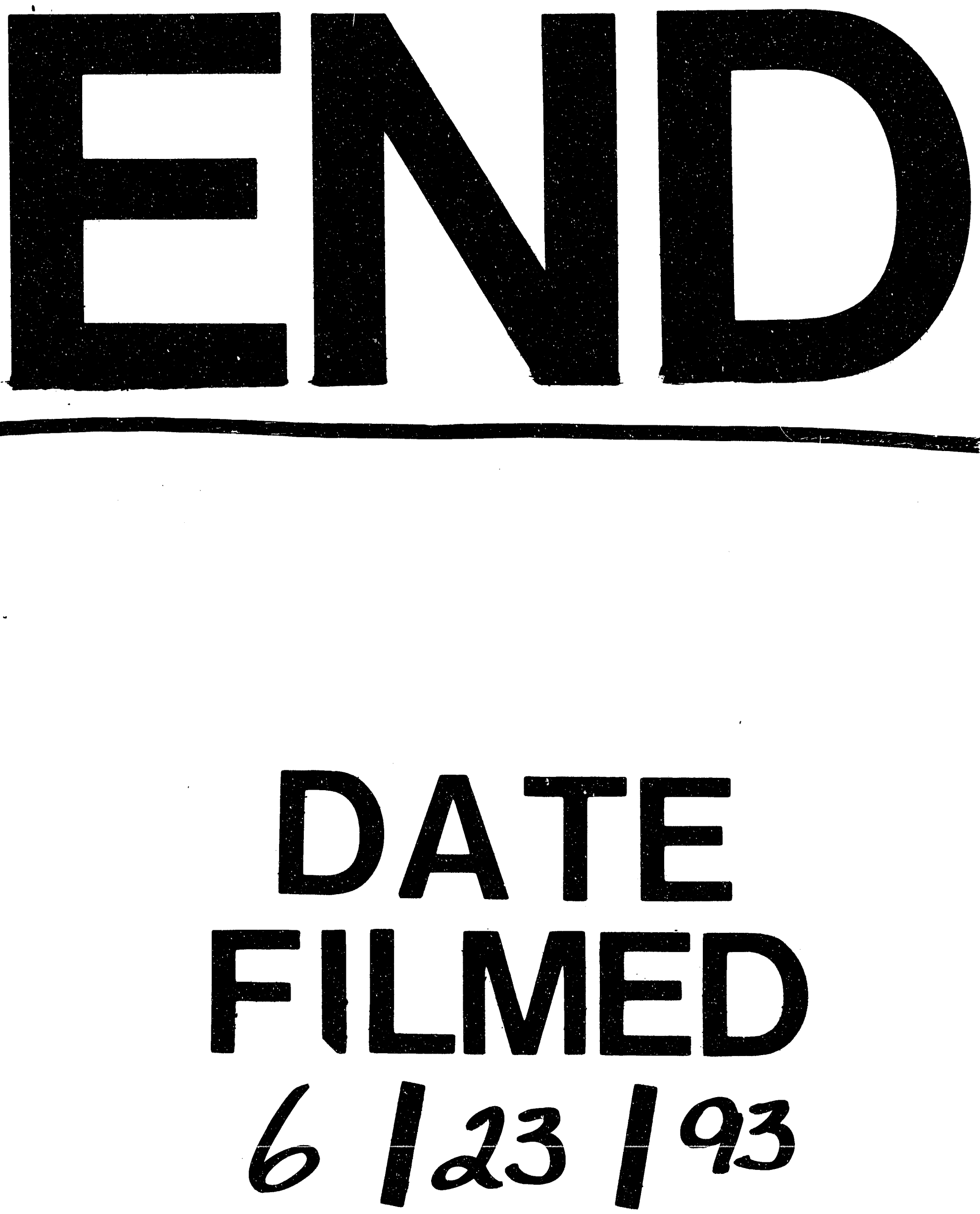
I 